\title{
Asian Desert Cutaneous Leishmaniasis
}

National Cancer Institute

\section{Source}

National Cancer Institute. Asian Desert Cutaneous Leishmaniasis. NCI Thesaurus. Code C34770

An acute necrotizing form of cutaneous leishmaniasis caused by Infection with leishmania tropica major. 